\title{
A Phenotype-Based Approach for the Substrate Water Status Forecast of Greenhouse Netted Muskmelon
}

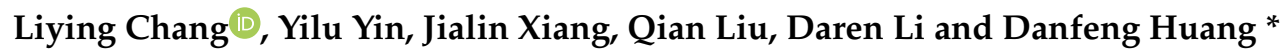 \\ School of Agriculture and Biology, Shanghai Jiao Tong University, Shanghai 200240, China; \\ Changly@sjtu.edu.cn (L.C.); yyl0926@sjtu.edu.cn (Y.Y.); jocelyn_xjl@alumni.sjtu.edu.cn (J.X.); \\ liuqiansmd@sjtu.edu.cn (Q.L.); chhblidaren@sjtu.edu.cn (D.L.) \\ * Correspondence: hdf@sjtu.edu.cn; Tel.: +86-136-0168-2332
}

Received: 2 April 2019; Accepted: 6 June 2019; Published: 13 June 2019

\begin{abstract}
Cultivation substrate water status is of great importance to the production of netted muskmelon (Cucumis melo L. var. reticulatus Naud.). A prediction model for the substrate water status would be beneficial in irrigation schedule guidance. In this study, the machine learning random forest model was used to forecast plant substrate water status given the phenotypic traits throughout the muskmelon growing season. Here, two varieties of netted muskmelon, "Wanglu" and "Arus", were planted in a greenhouse under four substrate water treatments and their phenotypic traits were measured by taking the images within the visible and near-infrared spectrums, respectively. Results showed that a simplified model outperformed the original model in forecasting speed, while it only uses the top five most significant contribution traits. The forecast accuracy reached up to $77.60 \%$, $94.37 \%$, and $90.01 \%$ for seedling, vine elongation, and fruit growth stages, respectively. Combining the imaging phenotypic traits and machine learning technique would provide a robust forecast of water status around the plant root zones.
\end{abstract}

Keywords: muskmelon; phenotype; random forest algorithm; cultivation substrate water status; forecasting

\section{Introduction}

Netted muskmelon (Cucumis melo L. var. reticulatus Naud.) is a popular fruit in the fresh market due to its unique netted patterns, esthetically pleasing shape, high sugar content, and good taste, which makes netted muskmelon a widely planted fruit among growers worldwide. Currently, there are more than 460,900 hectares of netted muskmelon planted each year [1].

Growing netted muskmelon requires strict cultivation conditions and complex management strategies, particularly for the water status in the cultivation substrate [2,3]. Inadequate substrate water status would lead to yield loss, poor quality, low sugar content, and unaesthetic netted patterns [4-6]. Dogan et al. [7] discovered that cultivation substrate water content serves as a critical factor influencing sugar accumulation and specifically netted patterns formation. Therefore, it is necessary to regulate and control the substrate water content throughout all growing stages of netted muskmelon for quality improvement considerations.

Root zone water status is the moisture situation of plant root and is highly correlated to plant growing status [8]. Monitoring the substrate water status of plant root zone could help to establish an effective management strategy of precise irrigation in crop production. Several commercialized soil moisture sensors, such as tensiometer, neutron probes, and time domain reflectometry probes have been widely used in pot planting but they are limited in detecting the substrate water status because of the high cost and unreliable data collection. Furthermore, one probe only reflects the substrate water content of a single point rather than the water statuses of different pots [9-11]. 
With the development of sensing technology, real-time monitoring of physiological and ecological information of the plant itself provides an approach to indicate root zone water status [12]. Many studies have showed that the phenotypic traits of plant can reflect the water content of plants [13-16]. Phenotypic traits such as leaf area, leaf angle, and thermal temperature show strong correlations with the root zone water status [17]. Moreover, with the development of plant phenotypic monitoring technologies, now it is viable to carry out automatic high-throughput monitoring without damaging the plants, thus quickly acquiring the phenotypic traits and remarkably shortening the test cycle [18-20]. However, most of the plant-based irrigation methods are still at research/developing stage and little used yet for practice (except for thermal sensing in some situations). Systematical research on phenotypic traits selection for irrigation has seldom been reported.

A rapid and precise data analysis method is needed for plant-based information acquisition. The application of machine learning algorithm could be the solution. It is by easy data preparation, low computation complexity, fewer input factors, and availability to handle uncorrelated characteristics provides a solution for higher model forecast accuracy and better model adaptability [21]. Therefore, this algorithm can meet the need of high-throughput real-time monitoring. At present, many modern agricultural management technologies, such as agricultural internet of things (IOT) decision-making system [22], agricultural information construction, identification of crop diseases [23], and yield forecast [24], etc., have been created in aid with machine learning algorithm. Many studies have reported plant stress phenotyping using machine learning and prediction of plant water status, but few have focused on phenotyping root zone water stress $[25,26]$. It is crucial to detect plant water stress at the early stage before any damage observed with visible wilting, which affect subsequent plant growth and quality. Correlating root zone water status with plant phenotype to supervise irrigation system could be a practical way in precision irrigation system with easy operation and quick response. However, machine learning modeling in analyzing the phenotypic trait of greenhouse crops and judging their root zone water environment has seldom been used.

In this study, we obtained the phenotypic traits of greenhouse netted muskmelon by high-throughput phenotypic monitoring technology and built a classification forecast model for the water status of the netted muskmelon cultivation substrate using the random forest algorithm. The substrate water status of netted muskmelon at different growth stages can be determined in time, which offers a novel solution for the real-time irrigation of muskmelon.

\section{Materials and Methods}

\subsection{Materials and Treatments}

Experiment I was conducted in the greenhouse of Shanghai Zealquest Technology Co., Ltd, China (GPS coordinate: $31^{\circ} 11^{\prime} \mathrm{N}, 121^{\circ} 36^{\prime} \mathrm{E}$ ) from April to July in 2016. The experiment II as model validation was conducted in a multiplan greenhouse at Shanghai Jiaotong University, China $\left(31^{\circ} 11^{\prime} \mathrm{N}\right.$, $121^{\circ} 36^{\prime} \mathrm{E}$ ) from August to November in 2016, and the glasshouse heating, ventilation, and internal and external shading were all automatically regulated by Priva Software (Priva Company, Zuid Holland, the Netherlands) in these two experiments. Two cultivars of netted muskmelon, "Wanglu" with dense nettings and "Arus" with sparse nettings, were used in these two experiments. The muskmelon seedlings were first cultivated in plug at greenhouse, and then transplanted to pots at two-leaf and one-half stage. The muskmelons were vertically planted in pots with a total volume of $16 \mathrm{~L}$ of substrate containing 2:2:2:1 mixture of meteorite/perlite/peat/organic fertilizer. The bulk density and saturated water content were $0.21 \mathrm{~g} / \mathrm{mL}$ and $140 \%$, respectively.

For considering the feasibility of moisture level control and plant growth after transplanting, four relative water content levels were applied to these two experiments. The four water treatments with alternating 20\% 35\% relative water content (RWC), 35\% 50\% RWC, 50\% 60\% RWC, and 60\% 70\% RWC at seedling stage, 30\% 40\% RWC, 40\% 50\% RWC, 55\% 70\% RWC, and 70\% 85\% RWC at vine elongation stage, and 35\% 45\% RWC, 45\% 55\% RWC, 55\% 65\% RWC, and 65\% 80\% RWC at fruit 
development stage (Figure 1). Substrate water status was measured by the relative water content that was the percent of volumetric water content comparing to field water capacity. Due to the dynamic change of root zone moisture status, an upper limit was set for the moisture level of root zone. In other words, irrigation was stopped when the root zone moisture reached the upper limit. In this study, a Soil-watch Multi-parameter Monitoring System (Soil-Watch, Washington, USA) was used to measure the relative water content of root zone (\%). Five plants of each cultivar were randomly assigned to every treatment. Irrigation was conducted manually for all plants once a day according to the monitoring system.

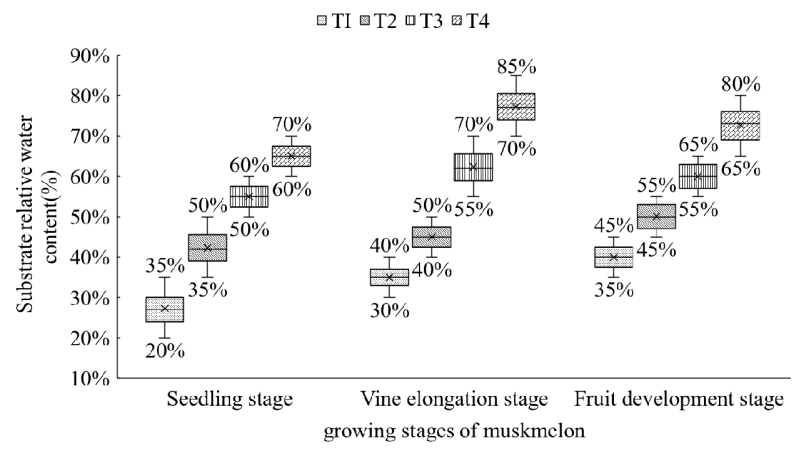

Figure 1. Substrate relative water content (\%) in four treatments at three growing stages of muskmelon. T1: $20 \% \sim 35 \%$ relative water content (RWC) at seedling stage, 30\% 40\% RWC at vine elongation stage, and 35\% 45\% RWC at fruit development stage. T2: 35\% 50\% RWC at seedling stage, $40 \% \sim 50 \%$ RWC at vine elongation stage, and 45\% 55\% RWC at fruit development stage. T3: 50\% 60\% RWC at seedling stage, 55\% 70\% RWC at vine elongation stage, and 55\% 65\% RWC at fruit development stage. T4: $60 \% \sim 70 \%$ RWC at seedling stage, 70\% 85\% RWC at vine elongation stage, and $65 \% \sim 80 \%$ RWC at fruit development stage.

\subsection{Image Acquisition and Trait Extraction}

A commercial phenotyping system (Scanalyzer 3D, LemnaTec GmbH, Würselen, Germany) was used for image acquisition (Figure 2), and imaging was performed every three days during the whole growth period for experiment I and every week for experiment II. At each imaging day, a total of 40 potted plants were placed at a fixed position under certain lighting conditions in an imaging room, where the light background was consistent and obtained stable color values, and two types of image were acquired simultaneously. Phenotypic images taken within the visible and near-infrared spectrums (Figure 3) were collected from both the top and sides of these plants. A total of 2160 images were collected during the experiment I and 960 images during the experiment II.

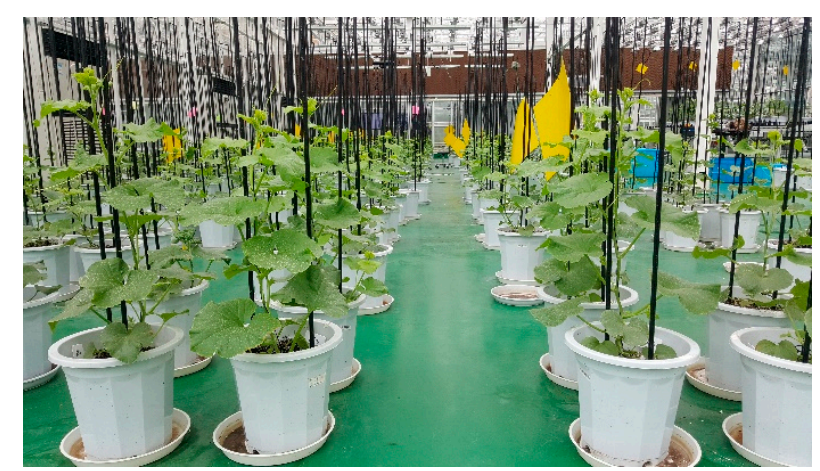

(a)

Figure 2. Cont. 


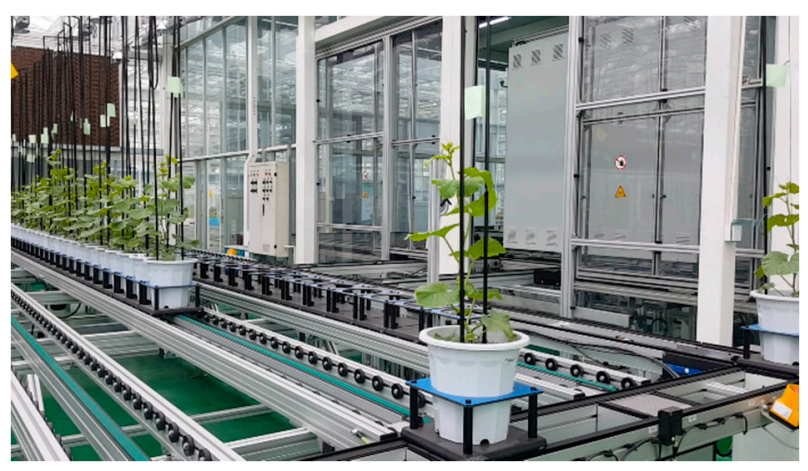

(b)

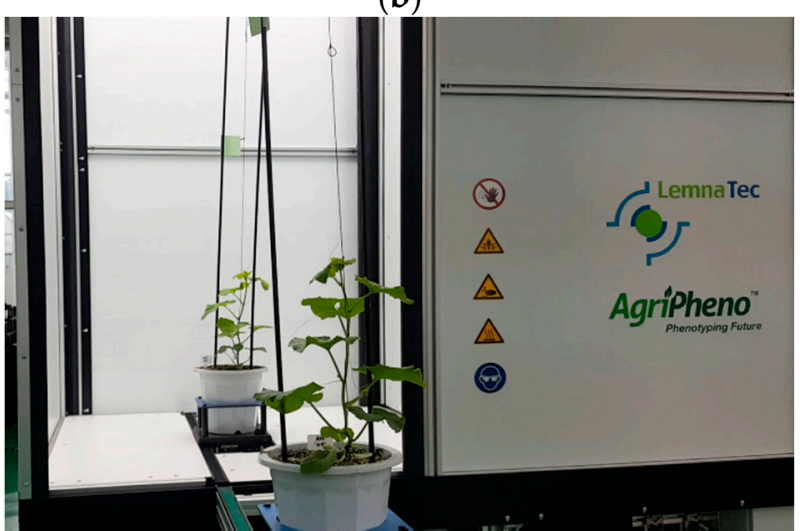

(c)

Figure 2. (a) Test site of plant cultivation, (b) automatic plant conveyors system, (c) Lemnatec 3D phenotyping system.

a

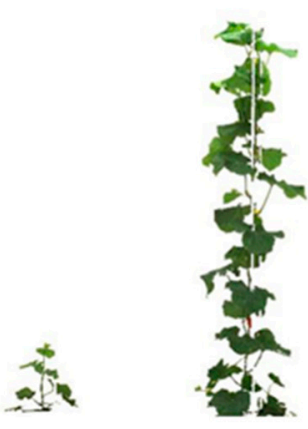

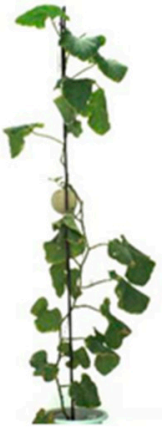

b

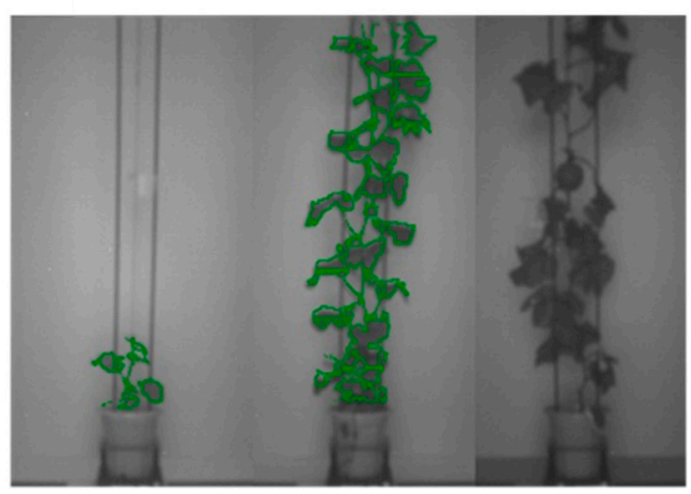

Figure 3. Muskmelon images acquired by Scanalyzer 3D (Lemna, Würselen, Germany) within visible (a) and near-infrared (b) spectra. From left to right of each panel were the images at seedling stage, vine elongation stage, and fruit development stage, respectively.

Phenotypic image processing steps (Figure 4) and image processing procedure in LemnaGrid consisted of four main steps shown as the flowchart in Figure 5: (1) image preprocessing, extracting target images from LemnaBase; (2) segmentation, separating target plant from the background in the image; (3) feature extraction, analyzing segmentation result and producing phenotypic traits; and (4) post-processing, summarizing feature extraction results of all target images and exporting as ".xls" file. 
a

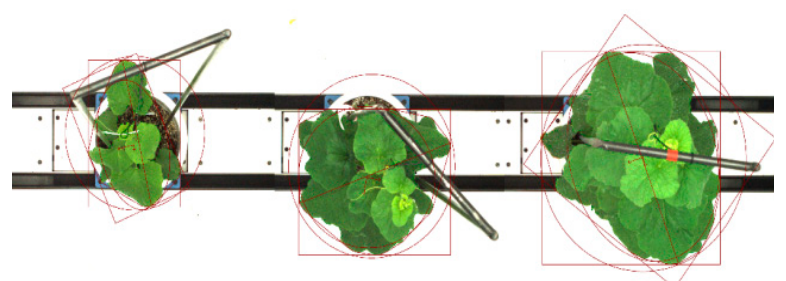

b

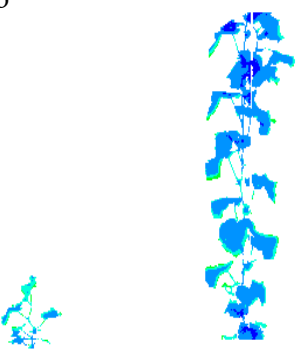

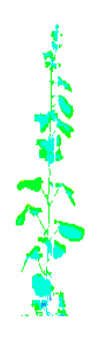

Figure 4. Phenotypic image processing steps. (a) Images within visible spectra;(b) Images within near-infrared spectra. Different colors represent different water contents in plants.

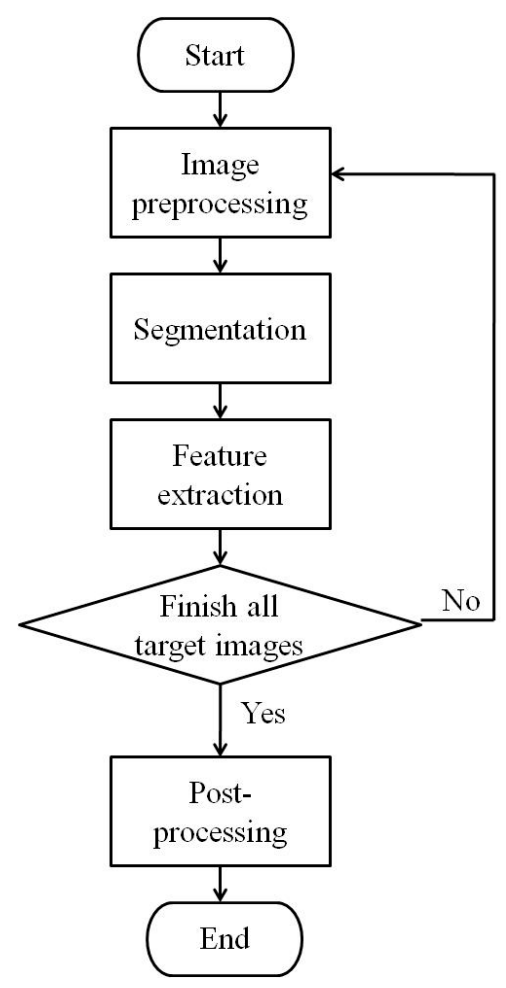

Figure 5. Flowchart of image processing procedure.

\subsection{Model Development of Substrate Water Status}

The development of substrate water status discrimination was consisted of three steps: (1) data preprocessing, data cleaning, data conversion, organizing data for phenotypic analysis; (2) phenotypic traits screening, removing those phenotypic traits with insignificant difference between treatments of substrate moisture level; (3) model development, using random forest modeling algorithms to classify substrate water status. MetaboAnalyst statistical analysis module (http://www.metaboanalyst.ca) was implemented for data preprocessing and phenotypic traits screening, and R language (windows, 3.3.3 version, $\mathrm{R}$ core Team, 2016) was implemented for model development. 


\subsection{Data Preprocessing}

In MetaboAnalyst statistical analysis module, data of extracted phenotypic traits from each image were organized into one datasheet by sample number (row) and phenotypic trait (column). Columns with more than $50 \%$ empty cells were removed. In the case of columns with data missing but less than $50 \%$ empty cells, the value of these cells were replaced by with a small value (the half of the minimum positive values in the original data). All the trait values were normalized using an autoscaling method (mean-centered and divided by the standard deviation of each variable) [12].

\subsection{Phenotypic Traits Screening}

Among those phenotypic traits extracted by imaging processing, traits which are insignificantly relevant to treatments may influence the modeling accuracy. In this study, one-way analysis of variance (ANOVA) was applied to screen traits resulting an optimal set of explanatory variables for discrimination model development. Traits with P $>0.05$ (Fisher's LSD method) were excluded from the traits set. In addition, the result of ANOVA presented a preliminary overview of the significance of each trait to treatments [12].

\subsection{Model Development and Forecast Ability Assessment}

Random forest is an ensemble classifier that consists of many decision trees and outputs the class that is the mode of the class's output by individual trees. Random forest algorithm was developed by Leo Breiman [27], boasting the advantages in big data processing of excellent performance in datasets, resistance to overfitting, good noise immunity, and strong adaptability to datasets, fast training speed, easy realization, among others.

A random forest (RF) algorithm has two parameters, the number of decision-making trees (ntree) and the number of features that are used to find the best features (Mtry). In the experiment, Mtry $=1,2$, 5,8 and ntree $=500$ were tested for benchmarking the RF models with the highest prediction accuracy. The random forest package of $\mathrm{R}$ language [28] was used for modeling, and the model adopted the 10 -fold cross validation that has been repeated for three times for the training.

The total samples of experiment I were selected as the training dataset for model development and optimization and the experiment II as the test dataset. The data processing was used the IBM SPSS statistics 20 and the self-compiled script in R language version 3.3.3 (R Core Team). Data mining and standardization were implemented with the statistical and analytical modules of MetaboAnalyst 3.0 software(https://www.metaboanalyst.ca/). ConfusionMatrix. Train function was used to assess forecast ability of the random forest model, and the mean value of forecast accuracy for cultivation substrate water content for all growing stages was obtained.

\section{Results}

\subsection{Subsection}

\subsubsection{Extraction of Phenotypic Traits}

There were 2160 images captured at different growth stages throughout the experiment, and 29 traits of three categories were extracted (Figures $3-5$ and Table 1 ). These traits include 9 morphological traits and 6 color traits, 14 near-infrared feature traits, which were acquired from visible and near-infrared spectrums, respectively. 
Table 1. Phenotypic traits extracted from collected images of muskmelon.

\begin{tabular}{|c|c|c|c|c|c|}
\hline \multirow[b]{2}{*}{ Trait } & \multirow[b]{2}{*}{ No. } & \multirow[b]{2}{*}{ Description } & \multicolumn{3}{|c|}{ Difference among Four Water Treatments ${ }^{1}$} \\
\hline & & & Seedling Stage & $\begin{array}{c}\text { Vine } \\
\text { Elongation } \\
\text { Stage }\end{array}$ & $\begin{array}{c}\text { Fruit } \\
\text { Development } \\
\text { Stage }\end{array}$ \\
\hline Morphology & & & & & \\
\hline Projection area & 1 & Area of plant projection $\left(\mathrm{mm}^{2}\right)$ & $\stackrel{*}{-}$ & * & * \\
\hline Object Extent X & 2 & Minimum width of plant projection (mm) & * & * & $\stackrel{*}{*}$ \\
\hline Object Extent $Y$ & 3 & Minimum height of plant projection (mm) & * & $\stackrel{*}{*}$ & * \\
\hline DBX area & 4 & $\begin{array}{l}\text { Minimum external polygonal area of plant } \\
\text { projection }\left(\mathrm{mm}^{2}\right)\end{array}$ & * & * & 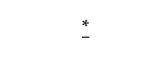 \\
\hline $\begin{array}{l}\text { Convex hull } \\
\text { circumference }\end{array}$ & 5 & 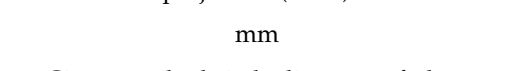 & * & $\stackrel{*}{-}$ & * \\
\hline Diameter & 6 & $\begin{array}{l}\text { Circumscribed circle diameter of plant } \\
\text { projection }(\mathrm{mm})\end{array}$ & NS & $\stackrel{*}{-}$ & $\stackrel{*}{-}$ \\
\hline Min rectangle area & 7 & $\begin{array}{l}\text { Minimum external rectangle area of plant } \\
\text { projection }\left(\mathrm{mm}^{2}\right)\end{array}$ & * & * & $\stackrel{*}{-}$ \\
\hline Compactness & 8 & Square of the object perimeter to object area & NS & * & * \\
\hline Eccentricity & 9 & $\begin{array}{l}\text { The ratio of the distance between the foci to } \\
\text { the length of the major axis }\end{array}$ & NS & * & * \\
\hline Invisible light & & & & & \\
\hline Mean blue index & 10 & $\begin{array}{l}\text { Mean blue index of muskmelon image within } \\
\text { RGB color space }\end{array}$ & NS & * & * \\
\hline $\begin{array}{l}\text { Variance of mean } \\
\text { blue index }\end{array}$ & 11 & $\begin{array}{l}\text { Variance of mean blue index of muskmelon } \\
\text { image within RGB color space }\end{array}$ & NS & * & * \\
\hline Mean green index & 12 & $\begin{array}{l}\text { Mean green index of muskmelon image } \\
\text { within RGB color space }\end{array}$ & * & * & NS \\
\hline $\begin{array}{l}\text { Variance of mean } \\
\text { blue index }\end{array}$ & 13 & $\begin{array}{l}\text { Variance of mean green index of muskmelon } \\
\text { image within RGB color space }\end{array}$ & * & * & * \\
\hline Mean red index & 14 & $\begin{array}{l}\text { Mean red index of muskmelon image within } \\
\text { RGB color space }\end{array}$ & * & * & * \\
\hline $\begin{array}{l}\text { Variance of mean } \\
\text { red index } \\
\text { Near-infrared } \\
\text { (NIR) }\end{array}$ & 15 & $\begin{array}{l}\text { Variance of mean red index of muskmelon } \\
\text { image within RGB color space }\end{array}$ & NS & * & * \\
\hline A1 & 16 & $\begin{array}{l}\text { Number of plant pixels with NIR intensity in } \\
122-138\end{array}$ & NS & $\stackrel{*}{-}$ & * \\
\hline R1 & 17 & $\begin{array}{l}\text { Ratio of plant pixels with NIR intensity in } \\
122-138\end{array}$ & NS & * & * \\
\hline A2 & 18 & $\begin{array}{l}\text { Number of plant pixels with NIR intensity in } \\
\qquad 154-170\end{array}$ & * & $*$ & * \\
\hline R2 & 19 & $\begin{array}{l}\text { Ratio of plant pixels with NIR intensity in } \\
\qquad 154-170\end{array}$ & * & * & * \\
\hline A3 & 20 & $\begin{array}{l}\text { Number of plant pixels with NIR intensity in } \\
\qquad 170-186\end{array}$ & $\stackrel{*}{-}$ & * & * \\
\hline R3 & 21 & $\begin{array}{l}\text { Ratio of plant pixels with NIR intensity in } \\
170-186\end{array}$ & NS & $\stackrel{*}{-}$ & * \\
\hline A4 & 22 & $\begin{array}{l}\text { Number of plant pixels with NIR intensity in } \\
\qquad 186-202\end{array}$ & $\stackrel{*}{-}$ & * & * \\
\hline $\mathrm{R} 4$ & 23 & $\begin{array}{l}\text { Ratio of plant pixels with NIR intensity in } \\
\qquad 186-202\end{array}$ & * & $*$ & $*$ \\
\hline A5 & 24 & $\begin{array}{l}\text { Number of plant pixels with NIR intensity in } \\
\qquad 202-218\end{array}$ & $\stackrel{*}{-}$ & $*$ & $*$ \\
\hline R5 & 25 & $\begin{array}{l}\text { Ratio of plant pixels with NIR intensity in } \\
\qquad 202-218\end{array}$ & * & * & * \\
\hline A6 & 26 & $\begin{array}{l}\text { Number of plant pixels with NIR intensity in } \\
218-234\end{array}$ & * & * & * \\
\hline R6 & 27 & $\begin{array}{l}\text { Ratio of plant pixels with NIR intensity in } \\
\qquad 218-234\end{array}$ & $\stackrel{*}{-}$ & $*$ & $*$ \\
\hline A7 & 28 & $\begin{array}{l}\text { Number of plant pixels with NIR intensity in } \\
\qquad 234-250\end{array}$ & * & * & * \\
\hline R7 & 29 & $\begin{array}{l}\text { Ratio of plant pixels with NIR intensity in } \\
234-250\end{array}$ & $*$ & * & NS \\
\hline
\end{tabular}

\footnotetext{
1 , the underlined ${ }^{*},{ }^{*}$, indicates the trait used in simplified random forest model. "NS" means no significant diffrences.
} 


\subsubsection{Analysis of Phenotypic Traits}

Phenotypic data were analyzed by one-way analysis of variance (ANOVA). As shown in Table 1 , at the seedling stage, 9 traits (diameter, compactness, eccentricity, mean blue, mean color blue variance, and mean color red variance, A1(Number of plant pixels with NIR intensity in 122-138), R1(Ratio of plant pixels with NIR intensity in 122-138) and R3(Ratio of plant pixels with NIR intensity in 170-186) showed no significant differences among four water treatments. At the fruit development stage, only two traits, mean color green and R7(Ratio of plant pixels with NIR intensity in 234-250), had no significant difference. At the vine elongation stage, all traits showed significant differences, and three traits, B6(Ratio of plant pixels with NIR intensity in 218-234), B3 (Ratio of plant pixels with NIR intensity in 170-186) and diameter, had the largest F-value among all treatments.

\subsubsection{Machine Learning Modeling and Forecast Ability Assessment of Phenotypic Traits}

Further, the traits showing significant difference $(\mathrm{P}<0.05)$ were standardized and imported to machine learning model, which included 18 traits at the seedling stage, 29 traits at the vine elongation stage, and 27 traits at the fruit development stage. Then, a random forest classification model was created to forecast cultivation substrate water content (Table 2). The forecasting accuracy from traits at seedling stage, vine elongation stage, and fruit development stage were $78.5 \%, 95.7 \%$, and $99.5 \%$, respectively. Among three growing stages of muskmelon, forecasting accuracy of random forest model at fruit development stage was the highest, while it took the longest forecast time costing $136.16 \mathrm{~s}$ due to input of a large number of traits.

Table 2. Random forest model parameters at the three growing stages of muskmelon.

\begin{tabular}{|c|c|c|c|c|c|c|c|c|}
\hline \multirow[b]{3}{*}{ Stage } & \multicolumn{8}{|c|}{ Random Forest Model } \\
\hline & \multicolumn{4}{|c|}{ Original } & \multicolumn{4}{|c|}{ Simplified } \\
\hline & Mtry & $\begin{array}{c}\text { Accuracy } \\
(\%)\end{array}$ & Kappa & Time-Consuming (s) & Mtry & $\begin{array}{c}\text { Accuracy } \\
(\%)\end{array}$ & Kappa & $\begin{array}{c}\text { Time-Consuming } \\
\text { (s) }\end{array}$ \\
\hline Seedling stage & 2 & 78.50 & 0.710 & 31.08 & 2 & 77.60 & 0.698 & 12.88 \\
\hline Vine elongation stage & 5 & 95.70 & 0.941 & 136.16 & 5 & 94.40 & 0.922 & 17.44 \\
\hline $\begin{array}{c}\text { Fruit development } \\
\text { stage }\end{array}$ & 5 & 99.50 & 0.993 & 30.46 & 1 & 90.00 & 0.846 & 11.14 \\
\hline
\end{tabular}

Confusion matrix was implemented to validate the developed models, and the average forecast accuracies of cultivation substrate water contents for all growing stages were obtained (Table 3). Among three growing stages of muskmelon, the lowest forecast accuracy of substrate water content was at seedling stage given the phenotypic traits, which was $78.48 \%$, while the highest forecast accuracy was obtained at fruit development stage based on the phenotypic trait data, which reached up to $99.55 \%$. Also, the forecast accuracy based on traits at vine elongation stage reached up to $95.74 \%$. All the accuracies from three growing stages could meet the needs of predicting substrate water content. The lowest forecast accuracy at seedling stage might be due to the less traits with significant difference among four water treatments. 
Table 3. Forecasting accuracy of substrate water content using Confusionmatrix.train function in random forest model at three growing stages of muskmelon.

\begin{tabular}{|c|c|c|c|c|c|c|c|c|}
\hline \multirow{2}{*}{ Stage } & \multicolumn{8}{|c|}{ Random Forest Model } \\
\hline & \multicolumn{4}{|c|}{ Original } & \multicolumn{4}{|c|}{ Simplified } \\
\hline \multicolumn{9}{|c|}{ Seedling stage } \\
\hline $\mathrm{T} 1$ & 20.5 & 1.2 & 0.6 & 1.2 & 19 & 1.5 & 1.8 & 2.7 \\
\hline $\mathrm{T} 2$ & 2.1 & 16.4 & 2.4 & 1.2 & 1.5 & 15.8 & 2.7 & 2.4 \\
\hline $\mathrm{T} 3$ & 2.4 & 0.3 & 25.9 & 4.2 & 2.4 & 0.3 & 25.9 & 4.2 \\
\hline $\mathrm{T} 4$ & 0.0 & 2.7 & 3.3 & 15.8 & 0.0 & 2.7 & 3.3 & 15.8 \\
\hline Mean & \multicolumn{4}{|c|}{0.785} & \multicolumn{4}{|c|}{0.776} \\
\hline \multicolumn{9}{|c|}{ Vine elongation stage } \\
\hline $\mathrm{T} 1$ & 9.8 & 0.8 & 0.0 & 0.0 & 9.8 & 1.0 & 0.0 & 0.0 \\
\hline $\mathrm{T} 2$ & 0.3 & 24.6 & 0.4 & 0.0 & 0.3 & 24.0 & 1.1 & 0.2 \\
\hline T3 & 0.7 & 0.7 & 29.6 & 0.5 & 0.7 & 0.7 & 28.8 & 0.5 \\
\hline $\mathrm{T} 4$ & 0.0 & 0.5 & 0.3 & 31.8 & 0.0 & 0.7 & 0.5 & 31.6 \\
\hline Mean & \multicolumn{4}{|c|}{0.957} & \multicolumn{4}{|c|}{0.944} \\
\hline \multicolumn{9}{|c|}{ Fruit development stage } \\
\hline $\mathrm{T} 1$ & - & - & - & - & - & - & - & - \\
\hline $\mathrm{T} 2$ & - & 24.0 & 0.5 & 0.0 & - & 17.6 & 3.7 & 0.0 \\
\hline T3 & - & 0.0 & 40.6 & 0.0 & - & 6.4 & 37.4 & 0.0 \\
\hline $\mathrm{T} 4$ & - & 0.0 & 0.0 & 34.9 & - & 0.0 & 0.0 & 34.9 \\
\hline Mean & \multicolumn{4}{|c|}{0.995} & \multicolumn{4}{|c|}{0.900} \\
\hline
\end{tabular}

-, not fruit set on the plant due to drought. Data were mean value of forecasting accuracy using three 10-fold crosscheck validation.

\subsubsection{Trait Contribution Analysis and Model Simplification}

In order to check the possibility of reducing phenotyping cost and model training time but without substantially decreasing the prediction accuracy, a sensitivity analysis was conducted to assess the contribution of each trait in the developed models. A simplified model with less explanatory variables was developed based on the contribution evaluation of traits for the model implemented in substrate water status detection. At the seeding stage of muskmelon, the top five most significant contribution traits for random forest modeling were the projection area, the number of plant pixels with near-infrared (NIR) intensity in 170-186 (A3), the number of plant pixels with NIR intensity in 186-202 (A4), the number of plant pixels with NIR intensity in 202-218 (A5), and the ratio of plant pixels with NIR intensity in 218-234 (R6). The top five most significant contribution traits at vine elongation stage refer to the minimum height of plant projection (min height), the convex hull circumference, the circumscribed circle diameter of plant projection (diameter), the number of plant pixels with NIR intensity in 122-138 (A1), and the ratio of plant pixels with NIR intensity in 170-186 (R3). However, the top five most significant contribution traits were all morphology traits at fruit development stage, and they were the minimum width of plant projection ( $\mathrm{min}$ height), the minimum external polygonal area of plant projection (min EP projection area), the convex hull circumference, the circumscribed circle diameter of plant projection (diameter), and the minimum external rectangle area of plant projection (min rectangle area) (Table 1). Thus, the top five traits in terms of contribution values were used in the simplified random forest modeling (Table 1), and they are varied among different growth stage models. Although the model was simplified, the forecasting accuracy of substrate water content remains high value for all the three growing stages of muskmelon.

Confusion matrix was implemented to validate the simplified random forest model. Results showed that the mean value of forecasting accuracy for cultivation substrate water content decreased by $0.90 \%, 1.30 \%$, and $9.50 \%$ at seedling stage, vine elongation stage, and fruit development stage, respectively (Table 3). Although the forecasting accuracy had a little decline, it still meets the needs for forecasting of substrate water content in real practice. 


\section{Discussion}

This study developed a forecast method of substrate water status during plant growth by integrating phenotyping and machine learning techniques, and using muskmelon plants. Different phenotyping traits were from three growth stages and two muskmelon cultivars, three types of phenotyping traits, such as morphological traits, color traits, and near-infrared traits, were acquired as the inputs for the model. The model had high accuracy at three different stages, with the highest value as $94.37 \%$ at vine elongation stage, but the contribution of phenotyping traits to the model were varied among the three growth stages.

At the seedling stage of muskmelon, almost all the traits that are sensitive to water status and have a significant contribution value to random forest model are related to image-gray-level and can be acquired by near-infrared monitoring. Therefore, it can be concluded that under all water treatments, the morphology differences among muskmelons are too minor to be easily captured by the sensor, while the difference in image-gray-level under near-infrared monitoring was significant. This result is consistent with the findings by Chen et al. [29] and Story and Kacira [21] that the changes of leaf cell demonstrate the powerful reflectivity within the near-infrared region, and are consistent with the research results by Yang et al. [30] and Buddenbaum et al. [31] that indicated the NIR has the potential to provide for rapid, non-destructive assessment of the leaf water potential in plant seedlings. Therefore, forecasting of the plant substrate water status can be implemented through the near-infrared image data at seedling stage of muskmelon, but cannot be implemented at the other two growth stages.

The traits that were sensitive to the substrate water status and contributing a significant value to the random forest model are nearly all morphology traits at fruit development stage. This indicates that water has a significant effect on the morphology traits of melon, whose morphology traits contribute greatly to the random forest model. Therefore, it is possible to forecast the substrate water status by using the morphology traits at the fruit development stage. At the vine elongation stage, most of the sensitive traits refer to morphology and near-infrared spectrum traits. This result is consistent with the findings reported in the area of spectroscopy and remote sensing imaging, such as Möller et al. [28], Veysi et al. [32], Shivers et al. [33], Chen et al. [34], and Chen et al. [35], that the water stress and canopy water status of field crop can be effectively monitoring using optical imaging technology.

This study demonstrates the potential of the machine learning approach in forecasting the substrate water status based on complex plant phenotyping traits. This method could promote the plant-based irrigation decision-making and implementation in practice. Therefore, the accumulative effect of water stress on plant growth during the growing period should be minimized with real-time discrimination to control the potential yield loss. Our presented work is capable of serving as a basis and supporting for intelligent greenhouse management, especially for irrigation management. Population phenotyping and water status discrimination are also worth further study due to plant canopy mutual occlusion and growth competition. In this study, plant images and other phenotypic traits were taken under controlled light and background colors to ensure prediction consistency. In real practice, however, the lighting condition and background color are not as consistent, which impose severe interferences for the image acquisition consistency. Therefore, further research with on-site traits collection is needed.

\section{Conclusions}

In this study, the cultivation substrate water status of greenhouse muskmelon at different growing stages were predicted based on melon morphology, color, and near-infrared feature traits as the input parameters for the random forest classification model. Prediction reached high speeds of 12.88, 17.44, and $11.14 \mathrm{~s}$ and high accuracies of $77.60 \%, 94.36 \%$, and $90.01 \%$ at the seedling, vine elongation, and fruit development stages, respectively. The melon root rhizosphere water status of substrate can be forecasted through the minor changes of muskmelon phenotypic trait, thus providing a solution to the limited probe sensors monitoring area, instable data, and weak instantaneity. Therefore, phenotypic imaging combining machine learning modeling can effectively forecast the substrate water status of muskmelon at different growing stages. This demonstrates that monitoring plant phenotypic traits 
can be used to determine substrate water status, and the forecast of substrate water status can be implemented with random forest model.

Author Contributions: Data curation, L.C., Y.Y. and J.X.; Formal analysis, L.C. and J.X.; Investigation, Y.Y., J.X., Q.L. and D.L.; Methodology, L.C., Y.Y., J.X., Q.L. and D.L.; Project administration, L.C., D.H.; Supervision, D.H.; Writing — original draft, J.X.; Writing—review \& editing, L.C. and Y.Y.

Funding: This study was supported by the National Natural Science Foundation of China (NSFC) (No. 31471411) and the Shanghai Municipal Agricultural Commission, China (2017 3-8-4).

Conflicts of Interest: The authors declare no conflicts of interest.

\section{References}

1. Ministry of Agriculture and Rural Affairs of the People's Republic of China (MOARAPRC). Areas and yields of vegetable, watermelon, muskmelon, strawberry, and potato in 2015, China. China Veg. 2017, 1, 18. (In Chinese). Available online: http://www.cnki.com.cn/Article/CJFDTotal-ZGSC201701004.htm (accessed on 5 June 2019).

2. Contreras, J.I.; Plaza, B.M.; Lao, M.T.; Segura, M.L. Growth and nutritional response of melon to water quality and nitrogen potassium fertigation levels under greenhouse mediterranean conditions. Commun. Soil Sci. Plant Anal. 2012, 43, 434-444. [CrossRef]

3. Sharma, S.P.; Leskovar, D.I.; Crosby, K.C.; Ibraim, A.M.H.; Volder, A. Differential response of muskmelon (Cucumis melo L.) cultivars to deficit irrigation. Acta Hortic. 2016, 1112, 201-208. [CrossRef]

4. Sharma, S.P.; Leskovar, D.I.; Crosby, K.M.; Volder, A.; Ibrahim, A.M.H. Root growth, yield, and fruit quality responses of reticulatus and inodorus melons (Cucumis melo L.) to deficit subsurface drip irrigation. Agric. Water Manag. 2014, 136, 75-85. [CrossRef]

5. Cabello, M.J.; Castellanos, M.T.; Romojaro, F.; Martinez-Madrid, C.; Ribas, F. Yield and quality of melon grown under different irrigation and nitrogen rates. Agric. Water Manag. 2009, 96, 866-874. [CrossRef]

6. Yildirim, O.; Halloran, N.; Cavusoglu, S.; Sengul, N. Effects of different irrigation programs on the growth, yield, and fruit quality of drip-irrigated melon. Turk. J. Agric. For. 2009, 33, 243-255.

7. Dogan, E.; Kirnak, H.; Berekatoglu, K.; Bilgel, L.; Surucu, A. Water stress imposed on muskmelon (Cucumis melo L.) with subsurface and surface drip irrigation systems under semi-arid climatic conditions. Irrig. Sci. 2008, 26, 131-138. [CrossRef]

8. Afzal, A.; Duiker, S.W.; Watson, J.E. Leaf thickness to predict plant water status. Biosystems Eng. 2017, 156, 148-156. [CrossRef]

9. Peterson, B.J.; Graves, W.R. Responses to root-zone water content of shrub congeners from eastern north america and mediterranean california. HortScience 2013, 48, 715-719. [CrossRef]

10. Li, Y.J.; Yuan, B.Z.; Bie, Z.L.; Kang, Y. Effect of drip irrigation criteria on yield and quality of muskmelon grown in greenhouse conditions. Agric. Water Manag. 2012, 109, 30-35. [CrossRef]

11. Kim, J.Y.; Glenn, D.M. Multi-modal sensor system for plant water stress assessment. Comput. Electron. Agric. 2017, 141, 27-34. [CrossRef]

12. Guo, D.D.; Juan, J.X.; Chang, L.Y.; Zhang, J.J.; Huang, D.F. Discrimination of plant root zone water status in greenhouse production based on phenotyping and machine learning techniques. Sci. Rep. 2017, 7, 8303. [CrossRef] [PubMed]

13. Kaneda, Y.; Shibata, S.; Mineno, H. Multi-modal sliding window based support vector regression for predicting plant water stress. Knowl.-Based Syst. 2017, 134, 135-148. [CrossRef]

14. Goldstein, A.; Fink, L.; Meitin, A.; Bohadana, S.; Lutenberg, O.; Ravid, G. Applying machine learning on sensor data for irrigation recommendations: revealing the agronomist's tacit knowledge. Precis. Agric. 2018, 19, 421-444. [CrossRef]

15. Cubero, S.; Lee, W.S.; Aleixos, N.; Albert, F.; Blasco, J. Automated systems based on machine vision for inspecting citrus fruits from the field to postharvest - A review. Food Bioprocess Technol. 2016, 9, 1623-1639. [CrossRef] 
16. Tang, J.; Deng, L.M.; Chen, H.; Luan, T.; Ma, W.J. Research on maize leaf recognition of characteristics from transmission image based on machine vision. Scientia Agricultura Sinica 2014, 47, 431-440. (In Chinese). Available online: http://en.cnki.com.cn/Article_en/CJFDTOTAL-ZNYK201403004.htm (accessed on 5 June 2019).

17. Kacira, M.; Ling, P.P.; Short, T.H. Machine vision extracted plant movement for early detection of plant water stress. Trans. ASAE 2002, 45, 1147-1153. [CrossRef]

18. Ge, Y.F.; Bai, G.; Stoerger, V.; Schnable, J.C. Temporal dynamics of maize plant growth, water use, and leaf water content using automated high throughput RGB and hyperspectral imaging. Comput. Electron. Agric. 2016, 127, 625-632. [CrossRef]

19. Neilson, E.H.; Edwards, A.M.; Blomstedt, C.K.; Berger, B.; Moller, B.L.; Gleadow, R.M. Utilization of a high-throughput shoot imaging system to examine the dynamic phenotypic responses of a $\mathrm{C}_{4}$ cereal crop plant to nitrogen and water deficiency over time. J. Exp. Bot. 2015, 66, 1817-1832. [CrossRef] [PubMed]

20. Fahlgren, N.; Feldman, M.; Gehan, M.A.; Wilson, M.S.; Shyu, C.; Bryant, D.W.; Hill, S.T.; McEntee, C.J.; Warnasooriya, S.N.; Kumar, I. A versatile phenotyping system and analytics platform reveals diverse temporal responses to water availability in Setaria. Mol. Plant 2015, 8, 1520-1535. [CrossRef]

21. Story, D.; Kacira, M. Design and implementation of a computer vision-guided greenhouse crop diagnostics system. Mach. Vision Appl. 2015, 26, 495-506. [CrossRef]

22. Duro, D.C.; Franklin, S.E.; Dube, M.G. A comparison of pixel-based and object-based image analysis with selected machine learning algorithms for the classification of agricultural landscapes using SPOT-5 HRG imagery. Remote Sens. Environ. 2012, 118, 259-272. [CrossRef]

23. Pantazi, X.E.; Moshou, D.; Tamouridou, A.A. Automated leaf disease detection in different crop species through image features analysis and One Class Classifiers. Comput. Electron. Agric. 2019, 156, 96-104. [CrossRef]

24. Elavarasan, D.; Vincent, D.R.; Sharma, V.; Zomaya, A.Y.; Srinivasan, K. Forecasting yield by integrating agrarian factors and machine learning models: A survey. Comput. Electron. Agric. 2018, 155, 257-282. [CrossRef]

25. Raza, S.E.A.; Prince, G.; Clarkson, J.P.; Rajpoot, N.M. Automatic detection of diseased tomato plants using thermal and stereo visible light images. PLoS ONE 2015, 10. [CrossRef] [PubMed]

26. Rahaman, M.M.; Chen, D.J.; Gillani, Z.; Klukas, C.; Chen, M. Advanced phenotyping and phenotype data analysis for the study of plant growth and development. Front. Plant Sci. 2015, 6, 619. [CrossRef] [PubMed]

27. Breiman, L. Random Forests. Mach. Learn. 2001, 45, 5-32. [CrossRef]

28. Möller, M.; Alchanatis, V.; Cohen, Y.; Meron, M.; Tsipris, J.; Naor, A.; Ostrovsky, V. Use of thermal and visible imagery for estimating crop water status of irrigated grapevine. J. Exp. Bot. 2007, 58, 827-838.

29. Chen, D.J.; Neumann, K.; Friedel, S.; Kilian, B.; Chen, M.; Altmann, T.; Klukas, C. Dissecting the phenotypic components of crop plant growth and drought responses based on high-throughput image analysis. Plant Cell 2014, 26, 4636-4655. [CrossRef]

30. Yang, G.; Lu, W.; Lin, Y.; Luo, J.; Wang, C.; Meder, R.; Warburton, P.; Arnold, R. Monitoring water potential and relative water content in eucalyptus camaldulensis using near infrared spectroscopy. J. Trop. For. Sci. 2017, 29, 121-128.

31. Buddenbaum, H.; Stern, O.; Paschmionka, B.; Hass, E.; Gattung, T.; Stoffels, J.; Hill, J.; Werner, W. Using VNIR and SWIR field imaging spectroscopy for drought stress monitoring of beech seedlings. Int. J. Remote Sens. 2015, 36, 4590-4605. [CrossRef]

32. Veysi, S.; Naseri, A.; Hamzeh, S.; Bartholomeus, H. A satellite based crop water stress index for irrigation scheduling in sugarcane fields. Agric. Water Manag. 2017, 189, 70-86. [CrossRef]

33. Shivers, S.W.; Roberts, D.A.; McFadden, J.P. Using paired thermal and hyperspectral aerial imagery to quantify land surface temperature variability and assess crop stress within California orchards. Remote Sens. Environ. 2019, 222, 215-231. [CrossRef] 
34. Chen, H.B.; Li, J.H.; Liu, C.H.; Liu, D.C. Sugarcane leaf water potential model based on canopy spectral signature. J. Irrig. E Drain. 2014, 33, 92-96. (In Chinese). Available online: http://en.cnki.com.cn/Article_en/ CJFDTOTAL-GGPS201403020.htm (accessed on 5 June 2019).

35. Chen, Z.F.; Song, N.; Wang, J.L.; Sun, J.S. Leaf water potential estimating models of winter wheat based on hyperspectral remote sensing. Scientia Agricultura Sinica 2017, 50, 871-880. (In Chinese). Available online: http://en.cnki.com.cn/Article_en/CJFDTOTAL-ZNYK201705010.htm (accessed on 5 June 2019).

(C) 2019 by the authors. Licensee MDPI, Basel, Switzerland. This article is an open access article distributed under the terms and conditions of the Creative Commons Attribution (CC BY) license (http://creativecommons.org/licenses/by/4.0/). 